\title{
Optic neuritis in an urban black African community
}

Abstract

Purpose To describe the clinical profile of idiopathic optic neuritis in South African blacks.

Methods South African black patients with acute isolated idiopathic optic neuritis, treated and followed for at least 3 months at a large medical centre, were studied. Exclusion criteria were other causes of optic neuropathy (such as ischaemic optic neuropathy, toxins or Leber's hereditary optic neuropathy); all causes of optic neuritis (such as HIV, neurosyphilis, sarcoid or connective tissue disease); neurological disease outside of the optic nerves; and any race other than South African black. Patients underwent extensive ophthalmic, neurological, radiological, cerebrospinal fluid and blood assessment. Results Eighteen eyes of 10 patients were studied. The mean age was 35.7 years and 9 patients were female. Only 2 patients had truly unilateral optic neuritis, the other 8 having either bilaterally simultaneous or consecutive disease. Presenting visual acuity (VA) was less than 6/60 in 17 of 18 eyes, with severe dyschromatopsia in all eyes. Fifteen eyes had optic disc swelling. All patients were treated with corticosteroids. After at least 3 months follow-up only 6 eyes recovered VA of $6 / 12$ or better, with only 3 eyes recovering colour vision of $\mathbf{1 0 / 1 3}$ or better on Ishihara plate testing. No patient had multiple sclerosis (MS) in presentation, nor developed MS on follow-up.

Conclusion Idiopathic optic neuritis in black South Africans differs from that in whites. The higher prevalence of bilateral cases and of optic disc swelling, the weaker association with MS and the extremely poor visual outcome distinguish optic neuritis in black South Africans.

Key words Acute, Black Africans, Idiopathic, Isolated, Optic neuritis

Idiopathic optic neuritis in black African patients is poorly described. From South Africa, cases have been reported with multiple sclerosis (MS) and with neuromyelitis optica. ${ }^{1,2}$ Most of these cases were bilateral and associated with severe visual loss as well as significant nonophthalmic neurological deficit. AfricanAmericans with demyelinating optic neuritis had more severly affected visual acuities at onset and after 1 year follow-up compared with white patients. ${ }^{3}$ The Optic Neuritis Treatment Trial (ONTT) included 59 African-American patients whose 6 month visual acuities did not differ significantly from those of white ONTT patients. $^{3,4}$

In light of the small number of black patients with idiopathic optic neuritis studied and the conflicting reports on African-American patients, we undertook this pilot study to describe the clinical profile of acute isolated idiopathic optic neuritis in the urban black community which our medical centre serves.

\section{Patients and methods}

Baragwanath Chris Hani Hospital and its affiliated St John's Eye Hospital of Johannesburg (Soweto), South Africa serve a regional urban population of almost 3 million. Cases of optic neuropathy managed in this institution between January and July 1999 were referred to R.P. for neuro-ophthalmological assessment and follow-up.

The diagnosis of acute optic neuritis required the following criteria: visual loss which progressed over 2 or more days and reached peak visual deficit within 14 days, dyschromatopsia and decreased pupillary light reaction. Exclusion criteria were suspicion of Leber's hereditary optic neuropathy on the basis of a positive family history or fundal appearance, toxin or drug exposure, uveitis, vascular disease such as vasculitis or ischaemic optic neuropathy (ION), neurosyphilis diagnosed on the basis of positive serology and active cerebrospinal fluid (CSF), positive human immunodeficiency virus (HIV) type-1 serology, other neurological deficit such as cranial nerve palsies or myelopathy, or any race other than South African black.

From 26 consecutive cases of optic neuropathy, 20 were diagnosed as acute optic neuritis (initial episode or recurrent). Three of these patients had neurosyphilis, 4 were found to be HIV-seropositive, 2 had associated cranial nerve palsies, 1 had a transverse myelitis (and
R. Pokroy

G. Modi

D. Saffer

Department of Neurology

Baragwanath Chris Hani Hospital

University of Witwatersrand Johannesburg-Soweto South Africa

R.P. is visiting the Departments of Neurology and Ophthalmology of the University of the

Witwatersrand from Kaplan Hospital, Rehovot, Israel

Russell Pokroy, MD

Department of

Ophthalmology

Kaplan Hospital

76100 Rehovot, Israel

Fax/tel: +972 89493706

e-mail: pokroyr@yahoo.com

Received: 20 November 2000 Accepted in revised form: 6 March 2001 


\begin{tabular}{|c|c|c|c|c|c|c|c|c|c|c|c|c|c|c|}
\hline \multirow{2}{*}{$\begin{array}{l}\text { Patient } \\
\text { no. }\end{array}$} & \multirow[b]{2}{*}{ Sex } & \multirow{2}{*}{$\begin{array}{c}\text { Age } \\
\text { (years) }\end{array}$} & \multirow{2}{*}{$\begin{array}{l}\text { Clinical } \\
\text { course }\end{array}$} & \multirow{2}{*}{$\begin{array}{c}\text { Pain } \\
\text { with } \\
\text { eye } \\
\text { movement }\end{array}$} & \multicolumn{2}{|c|}{ Visual acuity } & \multicolumn{2}{|c|}{$\begin{array}{l}\text { Ishihara colour } \\
\text { plates (out of 13) }\end{array}$} & \multicolumn{2}{|c|}{$\begin{array}{l}\text { Optic disc } \\
\text { swelling }\end{array}$} & \multirow{2}{*}{$\begin{array}{l}\text { CSF } \\
\text { active }\end{array}$} & \multirow{2}{*}{$\begin{array}{c}\text { CSF } \\
\text { oligoclonal } \\
\text { bands }\end{array}$} & $\begin{array}{c}\text { Contrast } \\
\text { CT of }\end{array}$ & \multirow{2}{*}{$\begin{array}{l}\text { MRI peri- } \\
\text { ventricular } \\
\text { signals }\end{array}$} \\
\hline & & & & & $\mathrm{R}$ & L & $\mathrm{R}$ & $\mathrm{L}$ & $\mathrm{R}$ & $\mathrm{L}$ & & & orbits & \\
\hline 1 & $\mathrm{~F}$ & 34 & BS & + & $6 / 60$ & $1 / 60$ & 0 & 0 & + & + & - & - & $\mathrm{N}$ & ND \\
\hline 2 & M & 36 & BS & + & $1 / 60$ & $1 / 60$ & 0 & 0 & + & + & - & ND & $\mathrm{N}$ & ND \\
\hline 3 & $\mathrm{~F}$ & 44 & BS & + & NLP & NLP & 0 & 0 & + & + & - & - & $\mathrm{N}$ & - \\
\hline 4 & $\mathrm{~F}$ & 5 & BS & ? & NLP & NLP & 0 & 0 & + & + & + & ND & $\mathrm{N}$ & ND \\
\hline 5 & $\mathrm{~F}$ & 47 & $\mathrm{U}$ & + & $6 / 6$ & NLP & 12 & 0 & - & + & + & - & $\mathrm{N}$ & ND \\
\hline 6 & $\mathrm{~F}$ & 45 & $\mathrm{U}$ & + & LP & $6 / 6$ & 0 & 13 & + & - & - & ND & $\mathrm{N}$ & ND \\
\hline 7 & $\mathrm{~F}$ & 53 & $\mathrm{BC}$ & + & NLP & $1 / 60$ & 0 & 0 & + & + & - & - & $\mathrm{N}$ & - \\
\hline 8 & $\mathrm{~F}$ & 38 & $\mathrm{BC}$ & + & LP & LP & 0 & 0 & + & - & + & - & $\mathrm{N}$ & - \\
\hline 9 & $\mathrm{~F}$ & 28 & $\mathrm{BC}$ & - & $3 / 60$ & LP & 0 & 0 & - & - & - & ND & $\mathrm{N}$ & ND \\
\hline 10 & F & 26 & $\mathrm{BS}, \mathrm{BC}$ & + & LP & $6 / 9$ & 0 & 1 & + & + & - & - & $\mathrm{N}$ & - \\
\hline
\end{tabular}

Data in bold refer to the currently affected eye.

+, present; -, absent; R, right eye; L, left eye; BS, bilateral simultaneous; $B C$, bilateral consecutive; U, unilateral; NLP, no light perception; ND, not done; $\mathrm{N}$, normal.

was diagnosed as neuromyelitis optica) and 3 were not pure South African black. Seven remaining patients were prospectively entered into this study. Three additional patients, who had had well documented and investigated acute isolated idiopathic optic neuritis prior to January 1999 (patients 1, 3 and 10), and who were being regularly followed up (by ourselves), were included. The previous fellow-eye episodes of the patients with recurrent optic neuritis (patients 7-10) were also included.

Age at onset of symptoms of the most recent episode of optic neuritis, social background, ocular symptoms, neurological symptoms, Snellen chart visual acuity (VA) with best refractive correction (NLP, LP, 1/60, 3/60, $6 / 30,6 / 24,6 / 18,6 / 12,6 / 9,6 / 6)$, colour vision with Ishihara pseudoisochromatic colour plates or large red/green discs, pupillary light reactions, eye movements, visual fields (non-automated), optic disc appearance (direct and stereoscopic ophthalmoscopy), macular and peripheral retina (through dilated pupils), vitreous activity, anterior segment and intraocular pressure (applanation tonometry) of both eyes of each patient were assessed and followed up by R.P.

Patients underwent at least one ophthalmic examination by other ophthalmologists as well as neurological assessment by G.M., D.S. and other neurologists. Patients were re-examined weekly during the first 4-6 weeks. Subsequent follow-up was at monthly intervals until patients were clinically stable, at which point follow-up continued at 3 monthly intervals.

Blood investigations included collagen vascular disease screening (erythrocyte sedimentation rate (ESR), $C$-reactive protein(CRP), full blood count and platelets (FBC), antinuclear antigen (ANA) and rheumatoid factor $(\mathrm{RF})$ ), sarcoid screen (chest radiograph and angiotensin converting enzyme (ACE) level), infection screen (HIV, syphilis and toxoplasmosis serology) and nutritional assessment (serum vitamin $\mathrm{B}_{12}$ and folate).
CSF manometry and evaluation for protein, cells, syphilis, tuberculosis and fungal infections were performed in all cases. The presence of oligoclonal banding in the IgG region was assessed by protein electrophoresis in 6 of the 10 study CSFs.

Brain and orbit computed tomography (CT) with contrast injection (Omnipaque, Schering, Germany) was performed in all patients. Four patients underwent brain and orbit magnetic resonance imaging (MRI), which included T2-weighted and/or fluid-attenuated inverted inversion recovery (FLAIR) sequences. Fundal fluorescein angiography was performed in 2 patients in whom anterior ION was considered a possibility (patients over 45 years with marked unilateral optic disc swelling).

Patients were treated with intravenous methylprednisolone $1000 \mathrm{mg}$ /day for 3-5 days followed by oral prednisone $1 \mathrm{mg} / \mathrm{kg}$ /day to complete the 14 day treatment course, or with oral prednisone $1 \mathrm{mg} / \mathrm{kg} /$ day alone for 14 days. Following one of these treatment protocols, steroids were tapered rapidly.

\section{Results}

No patient presenting with the above clinical definition of acute isolated optic neuritis was excluded on the basis of pre-existing multiple sclerosis (MS). Eighteen eyes of 1 male and 9 female patients with acute isolated idiopathic optic neuritis were studied. Their clinical features at presentation are summarised in Table 1. Six patients had a single episode of optic neuritis and 4 had recurrent disease. Four were bilaterally simultaneous (BS), 3 bilaterally consecutive (BC), 1 both $\mathrm{BS}$ and $\mathrm{BC}$, and 2 unilateral.

Mean age was 35.7 years for the entire group, 35.3 years for the first-episode group and 36.3 years for the recurrent group. All patients, except patient 9, had periocular pain exacerbated by eye movement. This pain resolved in all patients on follow-up.

Presenting VA was less than 6/60 in all except 1 study eye. Presenting colour vision was also poor - all 18 eyes failed to read the Ishihara 12 test plate, although 7 eyes 


\begin{tabular}{|c|c|c|c|c|c|c|c|c|c|c|}
\hline \multirow[b]{3}{*}{ Patient no. } & \multirow{3}{*}{$\begin{array}{l}\text { Steroid } \\
\text { treatment }\end{array}$} & \multirow{3}{*}{$\begin{array}{c}\text { Significant } \\
\text { response to } \\
\text { steroid treatment }\end{array}$} & \multirow{3}{*}{$\begin{array}{l}\text { Duration of } \\
\text { follow-up } \\
\text { (months) }^{a}\end{array}$} & \multirow{3}{*}{$\begin{array}{c}\text { Optic } \\
\text { neuritis } \\
\text { recurrences }\end{array}$} & \multicolumn{6}{|c|}{ Clinical features at follow-up } \\
\hline & & & & & \multicolumn{2}{|c|}{ Visual acuity } & \multicolumn{2}{|c|}{$\begin{array}{c}\text { Ishihara colour plates } \\
\text { (out of 13) }\end{array}$} & \multicolumn{2}{|c|}{$\begin{array}{l}\text { Optic disc } \\
\text { swelling }\end{array}$} \\
\hline & & & & & $\mathrm{R}$ & $\mathrm{L}$ & $\mathrm{R}$ & $\mathrm{L}$ & $\mathrm{R}$ & $\mathrm{L}$ \\
\hline 1 & Oral & - & 10 & 0 & $6 / 12$ & $3 / 60$ & 0 & 0 & $\mathbf{T P}$ & OA \\
\hline 2 & Oral & + & 3 & 0 & $6 / 6$ & $6 / 12$ & 13 & 10 & $\mathbf{T P}$ & TP \\
\hline 3 & IV & - & 36 & 0 & NLP & NLP & 0 & 0 & OA & OA \\
\hline 4 & IV & - & 5 & 0 & LP & LP & 0 & 0 & OA & OA \\
\hline 5 & IV & - & 3 & 0 & $6 / 6$ & NLP & 13 & 0 & $\mathrm{~N}$ & $\mathbf{O A}$ \\
\hline 6 & Oral & - & 3 & 0 & $6 / 24$ & $6 / 6$ & 2 & 13 & $\mathbf{T P}$ & $\mathrm{N}$ \\
\hline 7 & IV & + & $8(48)$ & 3 & NLP & $6 / 12$ & 0 & 7 & $\mathrm{OA}$ & OA \\
\hline 8 & IV & + & $3(46)$ & 2 & LP & $6 / 30$ & 0 & 0 & $\mathrm{OA}$ & OA \\
\hline 9 & Oral & + & $4(9)$ & 1 & $6 / 6$ & LP & 12 & 0 & $\mathbf{N}$ & $\mathrm{OA}$ \\
\hline 10 & IV & + & $10(23)$ & 1 & $3 / 60$ & $6 / 9$ & 0 & 1 & OA & $\mathrm{TP}$ \\
\hline
\end{tabular}

Data in bold refer to the currently affected eye.

+ , present; -, absent; R, right eye; L, left eye; OA, optic atrophy of the entire disc; TP, temporal pallor; NLP, no light perception; $\mathrm{N}$, normal.

${ }^{a}$ Follow-up of the currently affected eye; total patient follow-up from the first episode is shown in parentheses.

were able to differentiate large red and green discs. All patients, except 2 of the recurrent group, had some degree of optic disc swelling of the affected eye. This varied from mild localised peripapillary nerve fibre layer swelling with mild disc hyperaemia to a markedly swollen raised disc with blurring of the entire disc margin. The optic disc of the fellow eye of the 2 patients with unilateral involvement was of normal colour and had normal-appearing vessels stemming from an average-sized cup. The vitreous, macular and peripheral retina were normal in both eyes of all patients. All study eyes demonstrated severe depression of their central visual field.

CSF showed increased protein level and/or lymphocytes in 3 patients. No oligoclonal bands were found in any of the 6 patients undergoing CSF protein electrophoresis.

CT findings were normal in all patients. There were no areas of increased contrast uptake. MRI studies were done in 4 patients, 3 of whom had recurrent optic neuritis. No abnormal periventricular white matter signals were seen in any patient, although all four MRI studies demonstrated two or more high-intensity T2-weighted or FLAIR signals, $>3 \mathrm{~mm}$ in size, at the grey matter-white matter interface.

Response to steroid treatment and the clinical features at 3 or more months of follow-up are shown in Table 2 and reported in the text as two groups. Response to steroid treatment was considered significant if VA improved by 2 or more levels (e.g. LP to $3 / 60$, or $1 / 60$ to $6 / 60$ ) within $72 \mathrm{~h}$ of commencing steroid treatment.

\section{First-episode group (patients 1-6)}

Six patients (10 eyes) had a single episode of optic neuritis. Follow-up ranged from 3 to 36 (median of 4, mean of 10) months. All patients received steroids ( 3 intravenous, 3 oral). Only 2 eyes (of the same patient) had a significant steroid response within $72 \mathrm{~h}$. Over at least 3 months of follow-up, 4 eyes (right eye of patients 1 and 6 , both eyes of patient 2) showed more than 3 levels of improvement in VA, 3 eyes recovered $6 / 12$ or better vision, and only 2 regained good colour vision by Ishihara plate testing $(\geqslant 10 / 13)$. All 4 of the improving eyes developed temporal pallor. The other 6 eyes in this group (left eye of patients 1 and 5, both eyes of patients 3 and 4) showed no improvement in visual function, and all went on to develop severe diffuse optic atrophy.

\section{Recurrent group (patients 7-10)}

Four patients (4 eyes) had recurrent optic neuritis. Follow-up of currently affected eyes ranged from 3 to 10 months. Total follow-up, from the initial episode of optic neuritis, ranged from 9 to 48 (mean of 32, median of 35) months. Patients 7 and 8 had multiple episodes of optic neuritis over a period of 3 years. Both patients had had severe unilateral optic neuritis of the right eye as their initial episode. Patient 9 had suffered severe unilateral optic neuritis of her left eye prior to the current episode. Patient 10 had suffered bilateral optic neuritis 13 months previously. Tables 1 and 2 record information pertaining to these patients' most recent attack of optic neuritis (boldface). All recurrences were in one eye only: the left eye of patients 7 and 8 and the right eye of patients 9 and 10 . Note that in 3 of these 4 patients the currently unaffected fellow eye was blind with severe optic atrophy from previous optic neuritis. All 4 patients of this group received steroid treatment (3 intravenous, 1 oral). All had a significant response to steroids. Visual acuity improved by more than 3 levels in 3 patients and by 2 levels in the fourth. In 2 patients VA recovered to $6 / 12$ or better. Two patients showed significant improvement in their Ishihara colour plate score. Six of the 8 affected eyes demonstrated diffuse, severe optic disc atrophy at follow-up.

Investigations for collagen vascular diseases were negative in all patients. Sarcoid screen (chest radiograph and serum ACE), ANA, RF and CRP were all within 
normal limits. Nutritional assessment, including serum vitamin $\mathrm{B}_{12}$ and folate, was within normal limits for all patients. No patient suffered from diabetes mellitus, hypertension or hypercholesterolaemia at the time of presentation (2 patients developed steroid-induced diabetes). No patient had vascular disease on general history and examination. Fluorescein angiography (performed in 2 patients to exclude anterior ION) demonstrated nerve fibre layer leakage with no obvious vascular abnormality.

\section{Discussion}

This combined retrospective and prospective study describes 18 eyes of 10 black South African patients with acute isolated idiopathic optic neuritis (6 first-episode, 4 recurrent). We studied this specific clinical entity by excluding other causes of optic neuropathy (such as ION, toxins or Leber's), all causes of optic neuritis (such as HIV, neurosyphilis, sarcoid or connective tissue disease), neurological disease outside of the optic nerves and any race other than South African black.

Differentiating optic neuritis and ION is often difficult. In our study optic neuritis was differentiated from ION by the presence of pain on eye movement, the absence of vascular risk factors (ischaemic heart disease, hypertension, diabetes mellitus, hypercholesterolaemia and current smoking) and the relatively young age. Furthermore, 4 patients had recurrence, another 4 had bilateral simultaneous disease and all affected eyes demonstrated central and not altitudinal visual field defects. Unaffected contralateral eyes did not have crowded discs, typical of the 'disc at risk' for ION. In 2 patients in whom ION was considered a possibility (albeit an unlikely one), fundal fluorescein angiography was performed and was consistent with optic neuritis.

The first-episode patients had poorer recovery of visual function than the recurrent-episode patients and a much poorer visual outcome than the ONTT patients. ${ }^{4}$ The recurrent group's initial episode of optic neuritis was their most severe. Patients 7,8 and 9 suffered an initial severe attack on optic neuritis from which vision barely improved (LP or worse), whereas all 4 of the recently affected second eyes had substantial visual recovery. A similarity between the initial episode of optic neuritis in both the first-episode and the recurrent groups was noted: both had a very poor visual outcome, most eyes developed severe diffuse optic atrophy and the mean patient age was similar.

The recurrent-episode patients were examined and followed by neurologists for a mean of 32 (median of 35) months. No other central nervous system signs or symptoms were found. Of the 3 patients who underwent MRI, none demonstrated abnormal periventricular signals, which is thought to be the MRI abnormality most specific for MS. 5,6 Three patients had CSF oligoclonal band testing, all with negative results. Allowing that recurrent optic neuritis (same or fellow eye) alone does not qualify as two sites, none of these 4 patients fulfilled the accepted criteria ${ }^{7}$ for either clinical or laboratorysupported MS.

Unfortunately only 4 study patients underwent MRI. Although no periventricular white matter lesions were seen, subcortical signals were seen in all 4 patients. In our population these subcortical signals are often seen in patients not suffering from demyelinating disease, although others ${ }^{5,6}$ have found them to be associated with MS. Further study of MRI in black patients with longterm follow-up would be useful.

Regarding steroid treatment in our black patients, in cases of severe optic neuritis $(\mathrm{VA}<6 / 60)$ our protocol is to treat with intravenous steroids within 30 days of disease onset. Certain study patients received oral steroids from their referring physicians. Whether steroid treatment is efficacious and whether intravenous prednisolone is preferable to oral prednisone in black South African patients with idiopathic optic neuritis would require a randomised, controlled study on our patient population, similar to the ONTT. ${ }^{8}$

Two further points of interest in our study were the high frequency of bilateral involvement and the high frequency of optic disc swelling. Bilateral disease was seen in 8 of the 10 study patients. Other studies ${ }^{1-3}$ also found that optic neuritis in blacks is usually bilateral. In contrast, optic neuritis in adults of Northern European origin is usually unilateral. ${ }^{9,10}$ Optic disc swelling was seen in most of our study patients (8 of 10 patients, 15 of 18 eyes), compared with the $34-40 \%$ found in the ONTT ${ }^{4}$ and in a recent English study. ${ }^{11}$ Phillips et al. ${ }^{3}$ found optic disc swelling in $50 \%$ of African-Americans with optic neuritis.

Our study is limited by the small number of patients and by a potential referral and patient-presentation bias towards the more severe cases (those not improving within 2-3 weeks). This potential bias only applies to a small proportion of our study patients since the majority presented primarily to the local primary care eye clinic (which is part of our institution) approximately 1 week after symptom onset.

Acute isolated idiopathic optic neuritis appears to be a distinct clinical entity in black South Africans. The high prevalence of bilateral cases, the high frequency of optic disc swelling, the weaker association with MS, the poor visual function on presentation and the extremely poor visual outcome were the main distinguishing features from optic neuritis in whites of Northern European origin. Furthermore, optic neuritis in blacks may be recurrent and appears to be distinct from both neuromyelitis optica and acute disseminated encephalomyelitis (which are not uncommon in blacks). ${ }^{3,12,13}$

The authors thank Dr Grant Maclaren and the ophthalmologists of St John's Eye Hospital for examining and referring some of the patients included in this study. 


\section{References}

1. Dean G, Bhigjee AIG, Bill PLA, et al. Multiple sclerosis in black South Africans and Zimbabweans. J Neurol Neurosurg Psychiatry 1994;57:1064-9.

2. Ames FR, Louw S. Multiple sclerosis in coloured South Africans. J Neurol Neurosurg Psychiatry 1977;40:729-35.

3. Phillips PH, Newman NJ, Lynn MJ. Optic neuritis in African Americans. Arch Neurol 1998;55:186-92.

4. Beck RW, Cleary PA, Backlund JC, and the Optic Neuritis Study Group. The course of visual recovery after optic neuritis: experience of the Optic Neuritis Treatment Trial. Ophthalmology 1994;101:1771-8.

5. Paty DW, Oger JJF, Kastrukoff LF, et al. MRI in the diagnosis of MS: a prospective study with comparison of clinical evaluation, evoked potentials, oligoclonal banding and CT. Neurology 1988;38:180-5.

6. Beck RW, Arrington J, Murtagh FR, Cleary PA, Kaufman DI, and the Optic Neuritis Study Group. Brain magnetic resonance imaging in acute optic neuritis. Arch Neurol 1993;50:841-6.
7. Poser CM, Paty DW, Scheinberg L, et al. New diagnostic criteria for multiple sclerosis: guidelines for research protocols. Ann Neurol 1983;13:227-31.

8. Beck RW, Cleary PA, Anderson MM, and the Optic Neuritis Study Group. A randomised, controlled trial of corticosteroids in the treatment of acute optic neuritis. N Engl J Med 1992;326:581-8.

9. Parkin PJ, Hierons R, McDonald WI. Bilateral optic neuritis: a long term follow-up. Brain 1984;107:951-64.

10. Morrissey SP, Borruat FX, Miller DH, et al. Bilateral simultaneous optic neuropathy in adults: clinical, imaging, serological, and genetic studies. J Neurol Neurosurg Psychiatry 1995;58:70-4.

11. Kapoor R, Miller DH, Jones SJ, et al. Effects of intravenous methylprednisolone on outcome in MRI-based prognostic subgroups in acute optic neuritis. Neurology 1998;50:230-7.

12. Osuntokun BO. The pattern of neurological illness in tropical Africa: experience at Ibadan, Nigeria. J Neurol Sci $1971 ; 12: 417-42$.

13. Cosnett JE. Multiple sclerosis and neuromyelitis optica: case reports and speculation. S Afr Med J 1981;60:249-51. 